\title{
Paediatric pleomorphic adenoma of sub mandibular gland - a uncommon occurrence
}

\author{
Dudda R. ${ }^{1}$, Bandiahanapalya Narasappa Y. ${ }^{2}$, M.H.P. ${ }^{3}$, Balaji N.K. ${ }^{4}$, Rangaiah S.T. ${ }^{5}$ \\ ${ }^{1}$ Dr. Ravi Dudda, Associate Professor, ${ }^{2}$ Dr. Yogesh Bandiahanapalya Narasappa, Postgraduate, ${ }^{3}$ Dr. Hanumantha Prasad \\ M., Professor and Head of The Department, ${ }^{4}$ Dr. Nagavara Kalegowda Balaji, Assistant Professor ${ }^{5}$ Dr. Sowmya Tumkur \\ Rangaiah, Senior Resident, all authors are affiliated with Department of Otorhinolaryngology, Mandya Institute of \\ Medical Sciences, Mandya, Karnataka, India.
}

Corresponding Author: Dr. Yogesh Bandiahanapalya Narasappa, Postgraduate, Department of Otorhinolaryngology, Mandya Institute of Medical Sciences, Mandya, Karnataka, India, Email: yogibplkmc@gmail.com

\begin{abstract}
Salivary glands tumours are rare, representing a wide variety of benign and malignant histologic subtypes, consisting of a group of heterogeneous lesions with complex clinico-pathological characteristics and distinct biological behaviours. Among salivary gland tumours incidence of pleomorphic adenoma in submandibular gland is $5-10 \%$ of the cases.

We report a case of 13 year oldmale patient who presented with a swelling in left submandibular region since 3 months. On clinical examination he was found to have a $3 \times 3 \mathrm{~cm}$ solitary non tender firm swelling palpable in left submandibular triangle. Remaining ENT examination clinically unremarkable. Ultrasonography of neck showed Hetero echoic lesion of about $3.0 \times 3.5 \mathrm{~cm}$ size in left submandibular gland with mild increased vascularity. Similar findings were noted in computed tomography of neck. Fine needle aspiration cytology of swelling showed features suggestive of Pleomorphic adenoma of submandibular gland. Patient underwent excision along with submandibular gland under general anaesthesia and post operative period procedure was uneventful. Histopathology of excised specimen was consistent with pleomorphic adenoma. Patient is on regular follow up with no post operative complications.
\end{abstract}

Keywords: Salivary glands, Hetero echoic, Pleomorphic adenoma

\section{Introduction}

Pleomorphic adenoma is the most frequent benign tumour of the salivary glands. Pleomorphic adenoma of submandibular gland accounts for only $8 \%$ among all salivary gland tumours. Pleomorphic adenoma isaslow growing tumour, histologically showing solid, tubuloglandular structure with alternate myxoid and chondroid zones [2]. Management is essentially surgical and post operative radiotherapy is advisable in larger masses to prevent recurrence [3].

\section{Case Report}

A 13 year old male patient presented to OPD of our hospital with history of swelling in left submandibular region for 3 months (Figure 1).

Clinical examination revealed $3 \times 3 \mathrm{~cm}$, solitary, non tender, firm swelling was bidigitally palpable in left submandibular region. Rest of the ENT examination was clinically unremarkable. Fine needle aspiration cytology of swelling showed a cellular aspirate composed of clusters and scattered epithelial cells which are round to oval with uniform round orthochromatic nuclei. In few of the cells the nuclei were eccentrically placed with abundant fibromyxoid stroma was seen- suggestive of pleomorphic adenoma. Ultrasonography of neck showed Hetero-echoic lesion of about $3.0 * 3.5 \mathrm{~cm}$ size in left submandibular gland with mild increased vascularity. Similar findings were noted on computed tomography of neck (Figure 2).

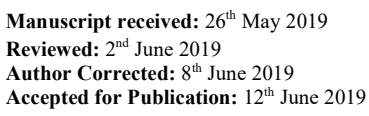




\section{Case Report}

Patient underwent excision along with submandibular gland under general anaesthesia. Procedure was uneventful. Histopathology of excised specimen showed feature of biphasic population of epithelial and mesenchymal components in the form of glandular elements against a chondromyxoid stroma. No hemorrhage /necrosis noted-suggestive of Pleomorphic adenoma of submandibular gland (Figure 3)

\section{Discussion}

Salivary gland tumours comprise only $1-4 \%$ of head and neck tumours with parotid gland is the most commonly affected salivary gland. Pleomorphic adenoma of submandibular gland accounts for only $8 \%$ among salivary gland tumours. Most frequent neoplasms in the submandibular glands are pleomorphic adenoma (36\%) followed by adenoid cystic carcinoma (25\%), mucoepidermoid carcinoma (12\%) and malignant mixed tumor (10\%). Clinical reports indicate that benign neoplasms were characterized by mostly painless swellings in submandibular triangle region [4].

Munir and Bradley reviewed series of the pleomorphic adenoma affecting submandibular gland over a period of 16 years from 1988 to 2004. All patients presented with clinically palpable mass of submandibular triangle among which $84 \%$ of cases were asymptomatic and $16 \%$ presented with pain. Most of the patients presented with painless submandibular swelling $42(84 \%)$ cases and $7(14 \%)$ with painful swelling. Clinically the tumour has the texture of cartilage and has an irregular and bosselated surface observed in all the patients [5].

Fine needle aspiration cytology findings provide evidence for a pre-operative diagnosis and also helps to differentiate between tumour and enlarged lymph nodes or inflammatory conditions. Final diagnosis is always based on histopathological finding of surgically excised specimen. Treatment of choice for pleomorphic adenoma of submandibular gland is total submandibular gland excision along with tumor [6].

Recurrence rate for submandibular gland tumours are less compared to parotid gland as entire gland is excised. Injury to the marginal mandibular nerve being the most common complication which may resolve spontaneously within a three months of period [7].

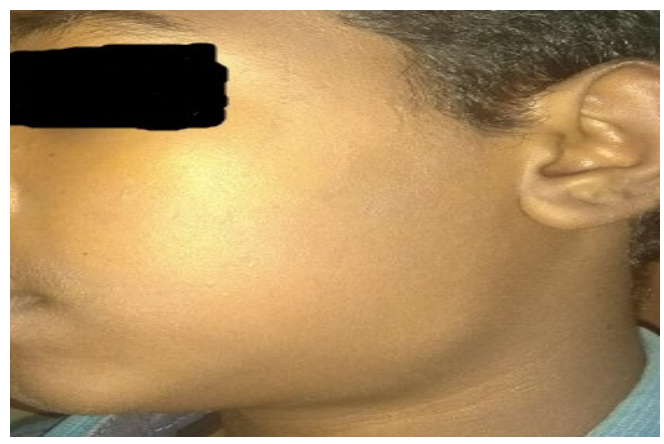

Figure-1: Swelling in left submandibular region

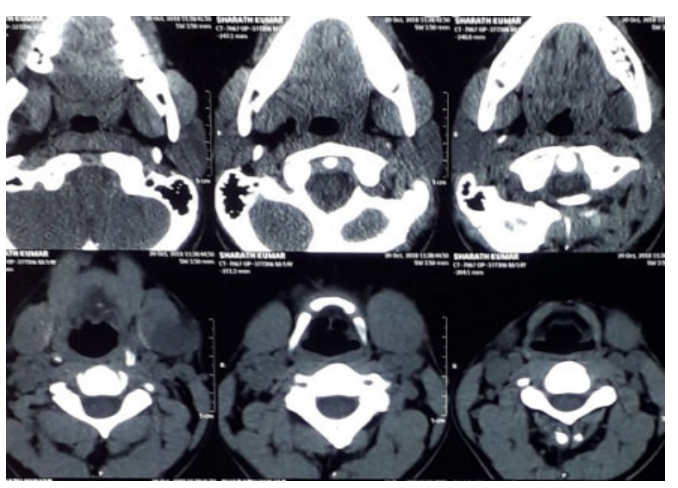

Figure-2: Heterogenously attenuated lesion with prominent enhancement in left submandibular gland 


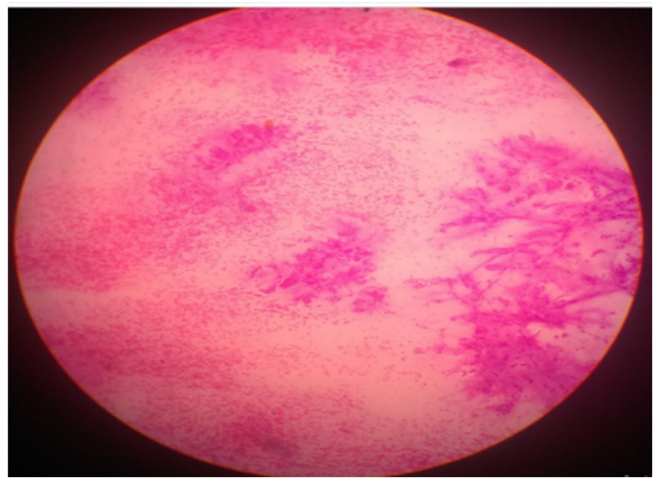

Figure-3: HPE- Feature of biphasic population of epithelial and mesenchymal components in the form of glandular elements against a chondromyxoid stroma

Funding: Nil, Conflict of interest: Nil Permission from IRB: Yes

\section{References}

1. Gajbhiye AS, Deshmukh MN, Jaipuriya PK, Jeughale KB, Kumar AA, Ghajbhare AP, et al. Pleomorphic adenoma of submandibular gland: not so common occurrence. Int Surg J 2018;5:657-61

2. Sohal BS, Verma SK, Gill GP, et al. Pleomorphic adenoma of submandibular gland. Indian J Otolaryngol Head Neck Surg. 2004 Jul; 56(3):216-7. doi: 10.1007/ BF02974354.

3. S Verma. A case of Huge Submandibular Pleomorphic Adenoma. The Internet Journal of Head and Neck Surgery. 2009 Volume 4 Number 2

4. Hanna E, Lee S, Fan C, Suen J. Benign neoplasms of the salivary glands. In: Cummings C, Flint P, Harker L, Haughey B, Richardson M, Robbins T. editors. Cummings Otolaryngology Head and Neck Surgery. Philadelphia: Mosby; 2005:1348-1377.
5. Munir N, Bradley PJ. Pleomorphic adenoma of the submandibular gland: an evolving change in practice following review of a personal case series. Eur Arch Otorhinolaryngol. 2007 Dec; 264 (12): 1447-52. Epub 2007 Jul 5. DOI: 10. 1007/ s00405- 0070378-x

6. Eveson JW, Cawson RA. Salivary gland tumours. A review of 2410 cases with particular reference to histological types, site, age and sex distribution. J Pathol. 1985 May;146(1):51-8.DOI:10.1002/path. 1711 460106

7. Hong KH, Yang YS. Surgical results of the intraoral removal of the submandibular gland. Otolaryngol Head Neck Surg. 2008 Oct;139 (4):530-4. doi: 10.1016/j. otohns. 2008.01.008.

\section{How to cite this article?}

Dudda R, Bandiahanapalya Narasappa Y, M.H.P, Balaji N.K, Rangaiah S.T. Paediatric pleomorphic adenoma of sub mandibular gland - a uncommon occurrence. Trop J Ophthalmol Otolaryngol.2019;4(2):178180.doi:10.17511/jooo.2019.i02.19 